\title{
Feed Water Line Cracking in Pressurized Water Reactor Plants
}

\author{
Somnath Chattopadhyay \\ Georgia Southern University, Statesboro, Georgia, \\ USA
}

\section{Introduction}

As early as 1979, a through wall crack was detected in a pressurized water reactor (PWR) plant. This crack initiated at the counter bore region of the pipe, adjacent to the weld joint attaching the pipe to the steam generator feed water nozzle. Subsequent inspection of the remaining feed water piping revealed cracking in the same vicinity but these were limited to partial wall penetration. As a result of this incident, the US Nuclear Regulatory Commission issued a directive to all operating plants requiring them to perform inspection of their feed water lines. The cracks were subsequently detected in the immediate vicinity of the steam generator nozzles in a number of plants. An exhaustive investigation was undertaken subsequently and this revealed that the primary cause of cracking was due to a fatigue loading mechanism induced by thermal stratification and high cycle thermal oscillations (striping) during low flow conditions.

Thermal stratification phenomenon results from a temperature differential across the pipe cross section with the top fluid stream hot and bottom stream relatively cold. During normal plant operations at low flow conditions, when the feed water nozzle is not completely full, hot water from the steam generator remains in the nozzle to fill up the rest of the volume. The difference in buoyancy between the hot and cold fluids inhibits their mixing so that the feed water becomes and remains thermally stratified. Separation of these two flow regions is due to the density difference in the hot and cold streams. The stratified temperature conditions can produce very high stresses, and can occur may times during normal low power operations; therefore this has the potential to initiate cracks in a relatively short period of time. Thermal striping is a local phenomenon that occurs at the interface between hot and cold flowing fluids. The interface level oscillates with periods ranging from 0.1 to 10 seconds. The oscillating fluid temperature gives rise to fluctuating stresses. The magnitudes of the striping stresses are not as high as those due to stratification itself, but the number of cycles is so large that they contribute significantly to fatigue crack initiation.

During normal plant operation, a series of temperature measurements has been taken around the pipe circumference at the vicinity of the of the feed water nozzle/pipe weld. Analysis of the data indicates that the stratified temperature distributions may be grouped into a handful of basic profiles corresponding to different levels of the interface between the hot and cold fluids. For analysis purposes these profiles could be assumed to be at steady state conditions because of their long duration observed during the tests. Nuclear piping systems (Class 1) are designed according to the rules of NB 3600 of the ASME Boiler and 
Pressure Vessel Code, Section III. The loads producing the stresses originate from the internal pressure, mechanical loads due to deadweight, seismic and thermal expansion and the operating thermal transients. Normally piping systems are not designed for circumferential temperature variation. The effect of the thermal stratification on the state of stress in the pipe is manifested in two ways: (a) the difference in temperature between the top and bottom of the pipe causes greater thermal expansion at the top tending to bow the pipe. When such bowing is restrained global bending stresses result; (b) the interface between the two fluid layers causes a local stress in the pipe due to thermal discontinuity across the pipe section. The fatigue damage produced by thermal stratification and the associated thermal striping are a good indication of the contribution of these phenomena to the observed feed water line cracking.

A detailed finite element stress analysis has been carried out using a three dimensional model that includes the steam generator shell, the feed water nozzle, and the elbow/pipe. The shell nozzle/elbow model contains three distinct regions with different heat transfer characteristics between the metal and the adjacent fluid. Each of the stratification profiles produces a complex state of stress throughout the nozzle and the elbow (pipe). Different levels of interface produce peak stresses at different locations around the circumference. Since the interface level varies during low flow operating conditions, each point in the counter bore area is subjected to a state of varying stresses of large magnitudes. A maximum range of stress intensity analysis was carried out prior to fatigue evaluation to determine whether the simplified elastic plastic analysis procedure would be required, and if so, to calculate the plastic intensification factor $K_{\mathrm{e}}$ by which the peak alternating stresses would be multiplied. The analysis predicted crack locations that that correlated well with the observed cracking.

The major cause of growth of the cracks is due to the thermal stratification cycles, which occur during low flows, primarily at hot standby. The thermal striping phenomenon or the oscillations occurring at the interface between hot and cold fluids has some influence on the crack growth, but it certainly impacts the crack initiation predictions. Thermal stratification causes a stress distribution in a pipe that is similar to what happens in a bimetallic strip. In the hot upper region compressive stresses develop as a result of constrained expansion, with the tensile stresses occurring in the lower region. This has been demonstrated using a simplified 2-dimensional finite element model. These are essentially the membrane stresses in the axial direction. Since the piping is flexible, the thermal moment gives rise to a bending stress that is added to the membrane stresses to obtain the total stresses.

It is suggested that the equations for obtaining stresses in piping systems as outlined in the ASME Code contain a term addressing circumferential temperature gradients in the pipe. A number of remedial measures have been implemented or suggested in operating power plants to minimize the stress amplitudes and frequency of load cycling during the stratification events.

In recent years, thermal stratification phenomenon has been observed to exist on several piping systems in pressurized water reactors. Damages have been observed in the main feed water lines, pressurizer spray lines, unisolable branch piping connected to reactor coolant piping, and pressurizer surge lines, with evidence linked to thermal stratification. The stratification phenomenon results from a temperature differential across the pipe crosssection with the top fluid stream hot and the bottom stream relatively cold. This condition occurs under relatively low flow conditions by cold feed injection into a stagnant hot pipe region or vice versa. Separation of two fluid flow areas is due to density differences in the 
hot and cold streams. This gives rise to gross thermal bending moments across the pipe section resulting in bowing deformation of the pipe.

In May 1979, a pressurized water reactor plant in operation approximately a year developed a through-wall crack in one of its feed water lines at the entrance to the steam generator. Subsequent investigation of the remaining lines revealed cracking in the same vicinity but limited to partial wall penetration. As a result of this incident, the United States Nuclear Regulatory Commission submitted a directive to all PWR operating plants to perform inspection of their feed water lines. A number of plants produced same degree of cracking in the same general area with wide variety of size, orientation and length of plant operation. Because of the involvement of many variables, it was impossible to immediately identify the specific mechanisms of crack initiation and growth. A number of activities were initiated to investigate the structural, thermal, hydraulic, operational and environmental conditions which individually or collectively contributed to the observed cracking.

\section{Observed crack locations}

Figure 1 illustrates the feed water pipe to steam generator nozzle junction where majority of cracking occurred. Cracks were found to be oriented circumferentially and located in the base metal outside the heat affected zone. There were intermittent pitting throughout the inside surface. The deepest cracks were found at the base of the counter-bore transition

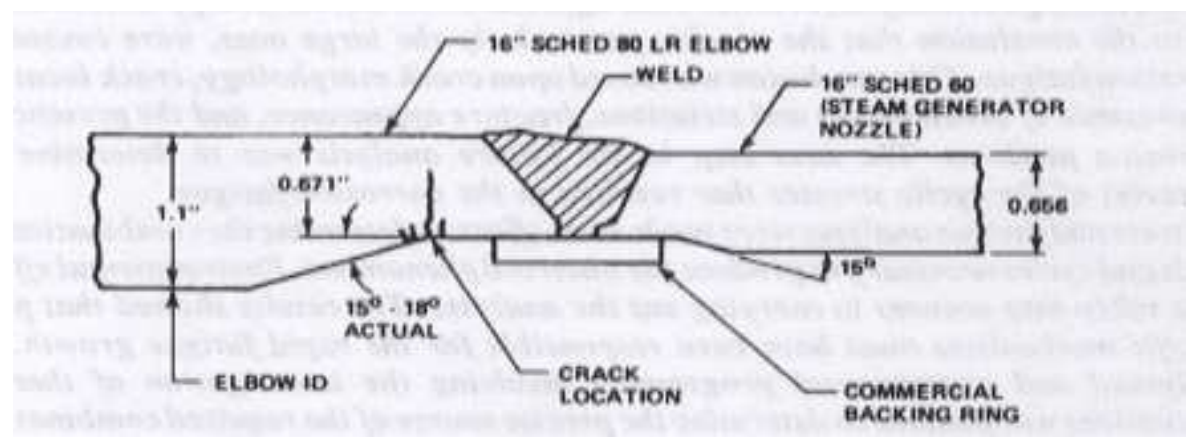

Fig. 1. Location of Cracks in PWR Feed water Pipe to Nozzle Attachment Region [1]

Typically a majority of PWR plants produced the circumferential cracking, the pattern of depth orientation varied considerably for different plants. Generally the deepest cracking was observed at the top, although in a number of plants this was found to occur at the sides, as well as the bottom. With the exception of one through-wall condition, most plants produced relatively small shallow cracks.

\section{Metallurgical studies}

The metallurgical investigations revealed that although corrosion may have been a major factor in initiating the cracks, the primary driving force for crack growth was mainly mechanical in nature. The corrosion fatigue may have resulted the cracking; both high and low cycle fatigue were involved, with high cycle initiating the fatigue and the low cycle propagating it. The fracture appearances were studied at high magnification by electron microscopy. Striations were found (Figure 2) substantiating the evidence that crack growth 
was taking place by fatigue, although the striation spacing was unreliable as a measure of the growth rate, since a large range of temperatures were involved $\left(200-450^{\circ} \mathrm{F}\right)$.

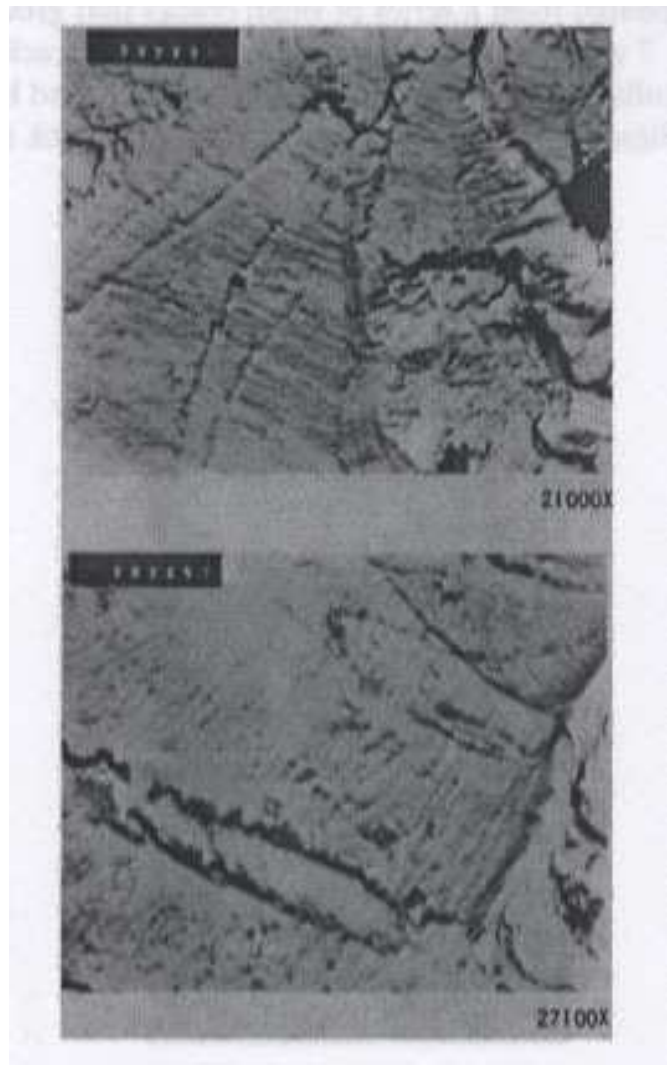

Fig. 2. Fractographs of the tip of a Deep Crack [1]

Instrumentations were installed at various plants to measure vibration and displacements of the feed water piping as well as temperatures in the vicinity of pipe to nozzle junction. The plants (both with and without observed cracking) were surveyed to determine their transient operation history and chemistry control. Particular attention was paid to the feed water oxygen content because of the presence of pitting. Thermocouple data of the on-site testing demonstrated the existence of persistent pipe thermal stratification during low feed water flow operations such as feed water makeup cycling during hot standby.

\section{Flow model studies}

Based on flow model tests it was shown that the temperature profile in a stratified cross section is mainly correlated with two thermal hydraulic parameters: (a) the flow rate in the line, and (b) the temperature difference between the top and the bottom of the pipe crosssection under consideration. The flow model test was a full scale feed line and nozzle assembly made of Plexiglas for visual observation and fluid temperature measurement 
(Figure 3). The test was designed to establish the temperature profile of the stratified water more accurately than the field measurements and to determine that thermal striping exists at the stratified interface, and if so determine the magnitudes and frequencies.

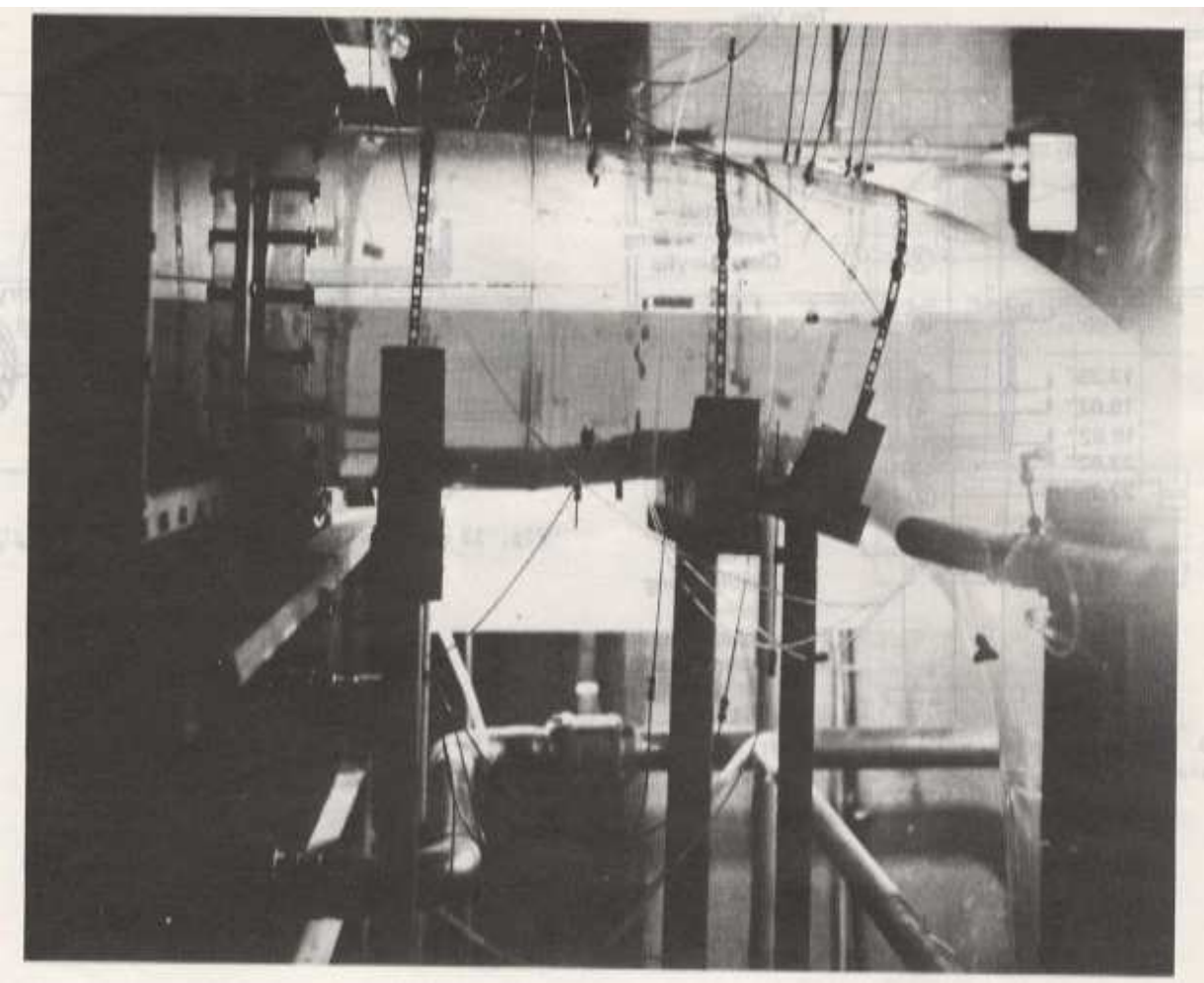

Fig. 3. Flow Model Test showing Stratification: upper clear layer hot water, lower gray layer cold saline solution [2]

The fluid temperature oscillations were recorded and it was subsequently confirmed that thermal striping mechanism led to feed line thermal fatigue.

\section{Structural analysis}

'During normal plant operation at low power conditions water is supplied to the steam generators at very low flow rates. When the flow rate is not high enough to completely fill the nozzle, hot water from the steam generator remains in the nozzle to fill up the rest of the volume. The difference in buoyancy between the hot and cold fluids inhibits their mixing so that the feed water becomes and remains thermally stratified as long as the flow rate is less that that required to completely fill the nozzle. During normal plant operation a series of temperature measurements was taken around the pipe circumference at the vicinity of the pipe weld. Analysis of the test data indicated that the stratified temperature distributions may be grouped into six basic profiles corresponding to different levels of the interface between the hot and cold fluids and are shown in Figure 4. 

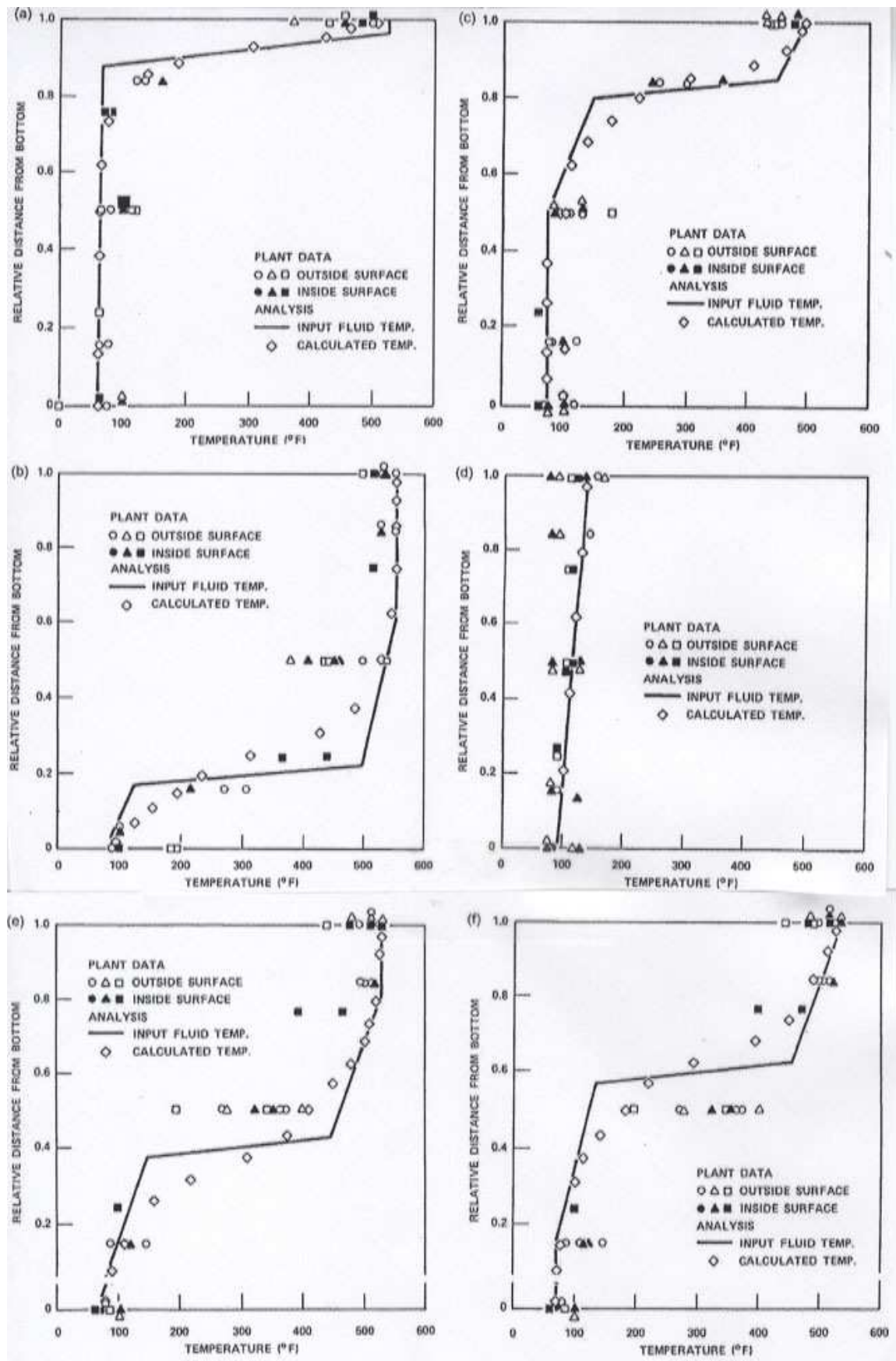

Fig. 4. Stratified Temperature Profiles [3] 
A finite element model has been prepared that includes a part of the steam generator shell, the feed water nozzle and the connecting elbow. The model uses 20-node isoparametric solid elements, two elements through the thickness and twelve around the circumference of the model.

The shell/nozzle/elbow model contains three distinct regions with different heat transfer characteristics between the metal and the adjacent fluid. The first region is that of the inside of the steam generator shell exposed to slowly moving hot water. The other regions are the section of the nozzle under the thermal sleeve, and the rest of the nozzle and the elbow.

Each of the stratification profiles produces a complex stress state throughout the nozzle and the elbow. The highest stresses occur in the weld counter bore region at the root of the elbow transition. For each profile there is a zone of compressive stress above the hot/cold interface and a region of tensile stress below it. Different interface levels produce peak stresses at different locations around the circumference. Since the interface level varies during low flow operating conditions, each point in the counter bore area is subjected to varying stress state.

Fatigue evaluations have been performed around the circumference for the counter bore transition root and along the top and side of the counter bore region. The load conditions and the number of cycles were combined with a pressure of 7.6 $\mathrm{MPa}$. A maximum range of stress intensity analysis was performed prior to each fatigue evaluation to determine whether the simplified elastic plastic analysis procedure would be required and if so, to calculate the plasticity intensification factors, $\mathrm{K}_{\mathrm{e}}$ factors by which the peak alternating stresses are to be multiplied.

The results for a typical plant fatigue evaluation [3] indicate that the peak usage factors are well above 1.0 and occur at the top and sides. These correlate with the observed locations of the deepest cracks for that plant. The high usage factors conclusively implicate thermal stratification and thermal striping during low flow conditions as prime contributors to the observed feed line cracking.

\section{Analytical studies}

An analytical technique has been developed to evaluate the stresses due to circumferential temperature gradient during thermal stratification. The associated numerical solution is an approximate one that uses the standardized profiles of Figure 4 . The mean temperatures at various circumferential pipe segments are calculated and shown in Figure 5.

The stress distributions for the Profiles 1 through 6 has been computed using the approximate numerical model and are shown in Figure 6.

The maximum range of stresses occurs at the top of the pipe and equals $72-(-124)=196 \mathrm{MPa}$ (based on profiles 2 and 1). Although the peak stress due to through the thickness temperature has not been explicitly considered, a conservative value of 2.0 is used. This makes the alternating stress amplitude as $196 \mathrm{MPa}$, which gives the allowable number of cycles about 30,000 using the design curve of [5]. The plant data in [4] indicates a comparable number of stratification temperature excursions. This leads to a significant fatigue usage factor at the top of the pipe that correlates with the fatigue cracks observed at this location. 


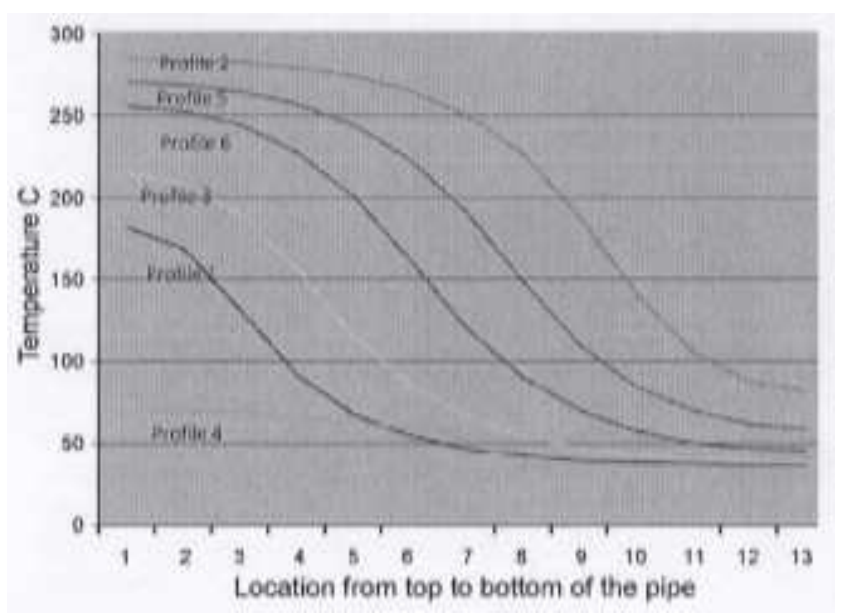

Fig. 5. Calculated Temperature input to the Approximate Numerical Model [4]

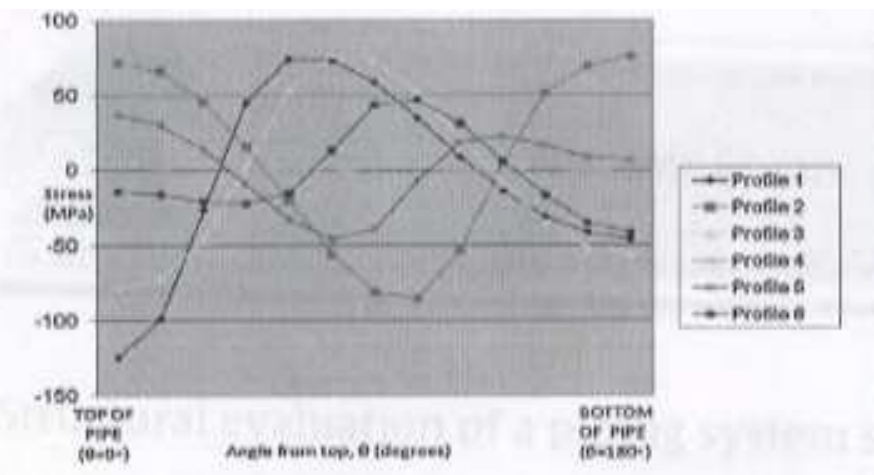

Fig. 6. Stress Distribution across Pipe Diameter for Profiles 1 through 6[4]

\section{References}

[1] Enrietto, J.F., Bamford, W. H., and White, D. H. (1981), "Preliminary Investigation of PWR Feed water Line Cracking, International Journal of Pressure Vessels and Piping, 9, pp. 421-443.

[2] Hu, M. H., Houtman, J. L., and White, D. H. (1981) “Flow Model test for the Investigation of Feed water Line Cracking for PWR Steam Generators, ASME Paper 81-PVP-4.

[3] Thurman, A. L., Mahlab, M. S., and Boylstein, R. E. (1981), “3-D Finite Element Analysis for the investigation of Feed water Line Cracking in PWR Steam Generators, ASME Paper 81-PVP-3.

[4] Chattopadhyay, S. (2009), "Structural Evaluation of a Piping System Subjected to Thermal Stratification," Nuclear Engineering and Design, 239, pp. 2236-2241.

[5] ASME Boiler and Pressure Vessel Code, 2010, Section III, Nuclear Power Components, American Society of Mechanical Engineers, New York. 


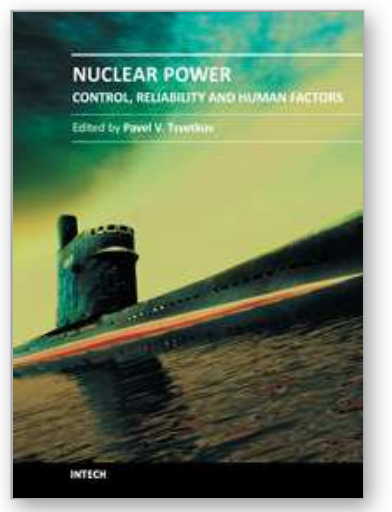

\author{
Nuclear Power - Control, Reliability and Human Factors \\ Edited by Dr. Pavel Tsvetkov
}

ISBN 978-953-307-599-0

Hard cover, 428 pages

Publisher InTech

Published online 26, September, 2011

Published in print edition September, 2011

Advances in reactor designs, materials and human-machine interfaces guarantee safety and reliability of emerging reactor technologies, eliminating possibilities for high-consequence human errors as those which have occurred in the past. New instrumentation and control technologies based in digital systems, novel sensors and measurement approaches facilitate safety, reliability and economic competitiveness of nuclear power options. Autonomous operation scenarios are becoming increasingly popular to consider for small modular systems. This book belongs to a series of books on nuclear power published by InTech. It consists of four major sections and contains twenty-one chapters on topics from key subject areas pertinent to instrumentation and control, operation reliability, system aging and human-machine interfaces. The book targets a broad potential readership group - students, researchers and specialists in the field - who are interested in learning about nuclear power.

\title{
How to reference
}

In order to correctly reference this scholarly work, feel free to copy and paste the following:

Somnath Chattopadhyay (2011). Feed Water Line Cracking in Pressurized Water Reactor Plants, Nuclear Power - Control, Reliability and Human Factors, Dr. Pavel Tsvetkov (Ed.), ISBN: 978-953-307-599-0, InTech, Available from: http://www.intechopen.com/books/nuclear-power-control-reliability-and-human-factors/feedwater-line-cracking-in-pressurized-water-reactor-plants

\section{INTECH}

open science | open minds

\section{InTech Europe}

University Campus STeP Ri

Slavka Krautzeka 83/A

51000 Rijeka, Croatia

Phone: +385 (51) 770447

Fax: +385 (51) 686166

www.intechopen.com

\section{InTech China}

Unit 405, Office Block, Hotel Equatorial Shanghai

No.65, Yan An Road (West), Shanghai, 200040, China

中国上海市延安西路65号上海国际贵都大饭店办公楼 405 单元

Phone: +86-21-62489820

Fax: $+86-21-62489821$ 
(C) 2011 The Author(s). Licensee IntechOpen. This chapter is distributed under the terms of the Creative Commons Attribution-NonCommercialShareAlike-3.0 License, which permits use, distribution and reproduction for non-commercial purposes, provided the original is properly cited and derivative works building on this content are distributed under the same license. 